\title{
Transcription Factor C/EBP $\alpha$ : Novel Sites of Expression and Cloning of the Human Gene
}

\author{
Guido W.M. Swart ${ }^{1, \star}$, Jan J.M. van Groningen', \\ Fred van Ruissen ${ }^{2}$, Mieke Bergers ${ }^{2}$ \\ and Joost Schalkwijk ${ }^{2}$ \\ Departments of Biochemistry ${ }^{1}$ and Dermatology ${ }^{2}$, \\ University of Nijmegen, P.O. Box 9101 , \\ NL-6500 HB Nijmegen, The Netherlands \\ * Corresponding author
}

We describe the characterization of recombinant clones for the human transcription factor CCAAT/enhancer binding protein alpha (hC/EBP $\alpha)$. The intronless hC/EBP $\alpha$ gene is almost $90 \%$ homologous to its rat and mouse counterparts. The gene copies of more distant species are less conserved, but the alignment reveals a striking homology in five regions, of which four may be involved in transactivation functions while the fifth concerns the carboxy-terminal bZip sequences (basic region and leucine zipper) mediating sequence specific DNA-binding. In addition to the usual expression sites, significant transcript levels were detected in the epidermal compartment of human skin and in rat aorta by northern analysis. The presence of hC/EBP $\alpha$ is further documented by immunohistochemical analysis of human skin biopsies and cultured keratinocytes showing the nuclear presence of the protein, notably in the suprabasal layers of the epidermis and in human keratinocytes induced to differentiate.

Key words: Aorta/Epidermis / Human transcription factor / C/EBP $\alpha$ / Keratinocytes.

\section{Introduction}

$\mathrm{C} / \mathrm{EBP} \alpha$ (CCAAT/enhancer binding protein alpha) was among the first cell/tissue specific transcription factors to be cloned, not in the least because of its abundance in liver nuclei and its DNA-binding specificities (virtually unrelated CCAAT-box elements of cellular promoters and viral enhancer sequences; (Landschulz et al., 1988a; Lincoln et al., 1994)). It appeared to be the first member of a subgroup of 'bZip' transcription factors. The 'bZip' motif consists of a dimerization domain, the leucine zipper, which is $\mathrm{N}$-terminally preceded by a stretch of basic amino acids mediating sequence specific DNA-binding (Landschulzetal., 1988b). High levels of C/EBP $\alpha$ expression are restricted to selected cells and tissues (notably hepatocytes and adipocytes, liver and fat tissue) and related to differentiation and growth arrest (Birkenmeier et al., 1989; Umek et al., 1991). C/EBP $\alpha$ was proposed to act as the 'central regulator of energy metabolism' on the basis that this transcription factor is involved in controlling the expression of a number of genes encoding proteins critical for specific metabolic processes in the liver and adipose tissue (Darlington et al., 1995). This proposal was recently confirmed since C/EBP $\alpha$ knockout mice died soon after birth because of an impaired energy homeostasis (Wang et al., 1995).

Other members of the C/EBP subgroup (e.g. C/EBPB/ NF-IL6; ref. Akira et al., 1990) are hardly detectable in normal tissues but are rather ubiquitously inducible by inflammatory stimuli. Members of the C/EBP subgroup form functional homo- and heterodimers, a prerequisite for interaction with the DNA target site (consensus $\mathrm{C} / \mathrm{T}$ NNNGNAAC/T) (Cao et al., 1991; Williams et al., 1991). The DNA contact surfaces of the members of the C/EBP subgroup (i.e. the basic region) are formed by nearly identical amino acid sequences and the dimerization domains are likewise highly homologous. Despite their intronless genomic structures, the genes for $\mathrm{C} / E B P \alpha$ and $C / E B P \beta$ encode multiple, related polypeptide chains due to alternative, in-frame initiation of translation (Descombes and Schibler, 1991; Ossipow et al., 1993; Lin et al., 1996). The shorter gene products have intact DNA-binding domains but lackimportant $\mathrm{N}$-terminal transactivating regions. As a consequence, they may act as inhibitors of transcription and counteract the full length products.

While the characterization of C/EBP $\alpha$ is primarily based on studies with recombinant clones and proteins from rodents (rat, mouse), a main purpose of our research is the characterization of differential gene expression and the responsible regulatory changes related to human diseases. Within this scope, we describe the characterization of recombinant human $\mathrm{C} / \mathrm{EBP} \alpha(\mathrm{hC} / \mathrm{EBP} \alpha)$ clones. The $\mathrm{hC} /$ $\mathrm{EBP} \alpha$ gene is highly homologous to its rodent counterparts. In addition to the usual expression sites, immunohistochemical analysis reveals significant levels of $\mathrm{hC} /$ EBP $\alpha$ in the suprabasal compartment of human epidermis. This finding suggests a role for hC/EBP $\alpha$ in terminal differentiation of epidermal keratinocytes.

\section{Results}

\section{Characterization of the Gene and a Partial cDNA for Human C/EBP $\alpha$}

The development of efficient biological tools to study $\mathrm{hC} /$ EBP $\alpha$ expression in normal and diseased human tissues requires detailed knowledge of the autologous sequence. For this purpose, we screened a human liver cDNA library with rat $\mathrm{C} / \mathrm{EBP} \alpha$ probes and isolated a partial clone of $\mathrm{hC}$ / 
EBP $\alpha$. This partial cDNA was successfully used as a probe to screen a genomic library prepared from human placenta. A cosmid vector was isolated carrying a $30 \mathrm{~kb}$ insert of genomic sequences encompassing the intronless $\mathrm{hC} /$ $\mathrm{EBP} \alpha$ gene. With the cosmid clone of $h \mathrm{~h} / \mathrm{EBP} \alpha$ as a probe, the gene was localized on chromosome 19q 13.1-
13.2 (data not shown), in agreement with already reported observations (Hendricks-Taylor et al., 1992).

After DNA sequence determination of the coding region (Figure $1 A$ ), the derived primary protein structure was compared with C/EBP $\alpha$ sequences available in the EMBL Genbank database (Figure 1B). The amino acid sequence

A

1 ATGGAGTCGg CCGACTTCTA CGAGGCGGA CCGCGGCCCC CGATGAGCAG CCACCTGCAG AGCCCCCCGC ACGCGCCCAG

CAGCGCCGCC TTCGGCTTTC CCCGGGGCGC GGGCCCCGCG CAGCCTCCCG CCCCACCTGC CGCCCCGGAG CCGCTGGGCG

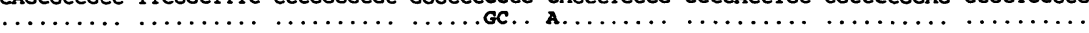
GCATCTGCGA GCACGAGACG TCCATCGACA TCAGCGCCTA CATCGACCCG GCCGCCTTCA ACGACGAGTT CCTGGCCGAC

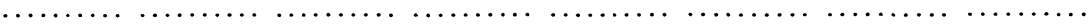
CTGTTCCAGC ACAGCCGGCA GCAGGAGAAG GCCAAGGCGG C-GTGGGCCC -ACG-GCGGC GGCGGCGGCG GCGACTTTGA CTACCCGGGC GCGCCCGCGG GCCCCGGCGG CGCCGTCATG CCCGGGGGAG CGCACGGGCC CCCGCCCGGC TACGGCTGCG CGGCCGCCGG CTACCTGGAC GGCAGGCTGG AGCCCCTGTA CGAGCGCGTC GGGGCGCCGG CGCTGCGGCC GCTGGTGATC AAGCAGGAGC CCCGCGAGGA GGATGAAGCC AAGCAGCTGG CGCTGGCCGG CCTCTTCCCT TACCAGCCGC CGCCGCCGCC GCCGCCCTCG CACCCGCACC CGCACCCGCC GCCCGCGCAC CTGGCCGCCC CGCACCTGCA GTTCCAGATC GCGCACTGCG GCCAGACCAC CATGCACCTG CAGCCCGGTC ACCCCACGCC GCCGCCCACT CCCGTGCCCA GCCCGCACCC CGCGCCCGCC

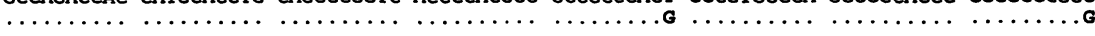
GTCGGTGCCG CCGGCCTGCC GG-CCCTGGC GAGCGCGCTC AAGGGGCTGG GCGCCGCGCA CCCCGACCTC CGCGCGAGTG

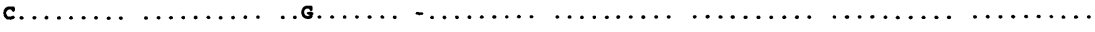

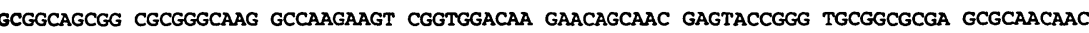

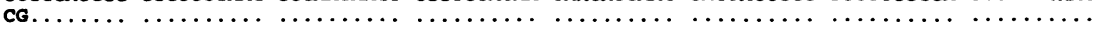

881 ATCGCGGTGC GCAAGAGCCG CGACAAGGCC AAGCAGCGCA ACGTGGAGAC GCAGCAGAAG GTGCTGGAGC TGACCAGTGA

961 CAATGACCGC CTGCGCAAGC GGGTGGAACA GCTGAGCCGC GAACTGGACA CGCTGCGGGG CATCTTCCGC CAGCTGCCAG 1041 AGAGCTCCTT GGTCAAGGCC ATGGGCAACT GCGCGTGA

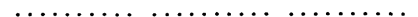

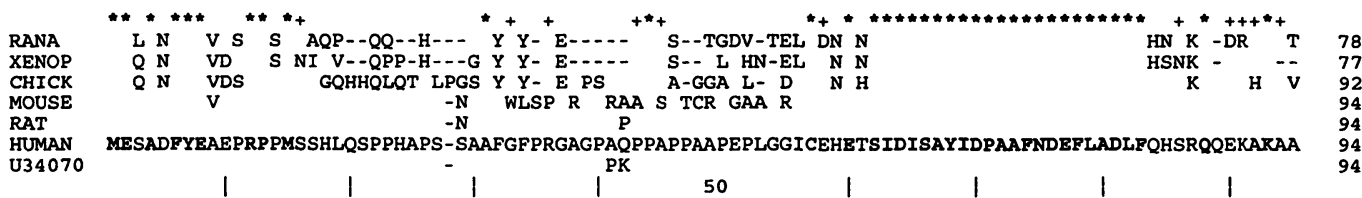

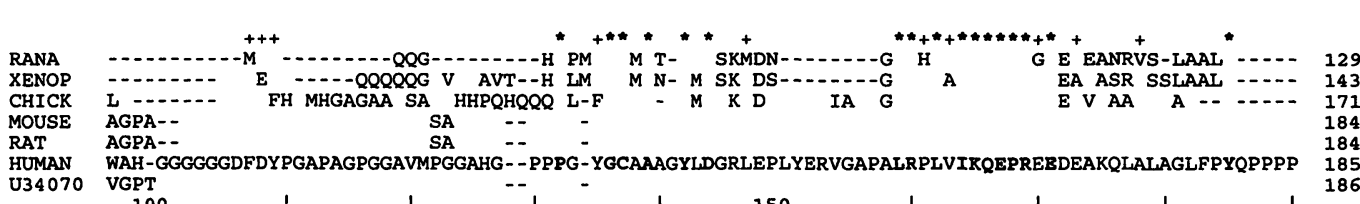

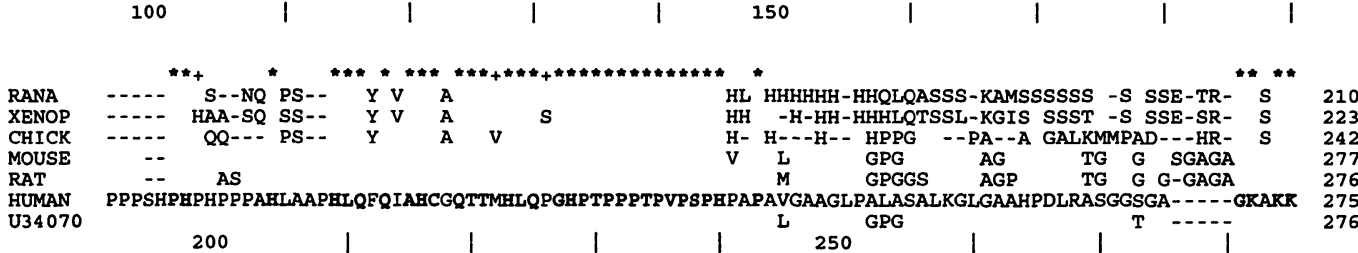

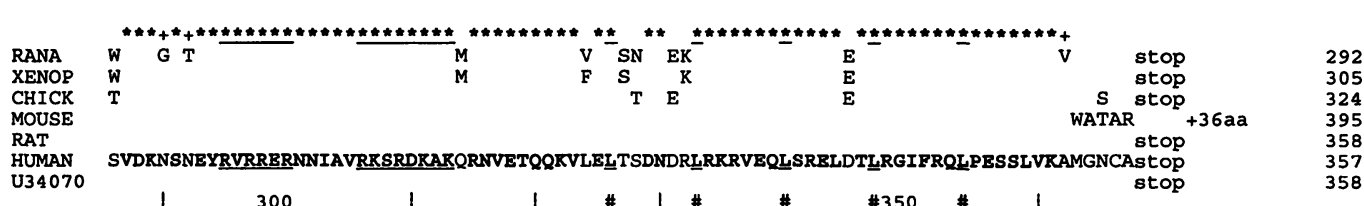

Fig. 1 Nucleotide Sequence of the hC/EBP $\alpha$ Coding Region (A) and Amino Acid Alignment with C/EBP $\alpha$ Isoforms of Other Species (B). (A) The nucleotide sequence of the $\mathrm{hC/EBP} \alpha$ coding region as determined by us (upper line) is compared with sequence U34070 (EMBL/Genbank; lower line). The 13 differences are highlighted by bold characters. (B) Database polypeptide sequences for C/EBP $\alpha$ are compared with the human sequence as determined by us (HUMAN). Identical amino acids are indicated by empty spaces, amino acid deletions by dashes. Completely conserved amino acids are indicated by asterisks on the top line. The two DNA contacting sequences in the basic region (box I and box II, respectively) are underlined, while the essential leucine residues in the zipper region are indicated by the symbol \# on the bottom line and by underlining. 
A

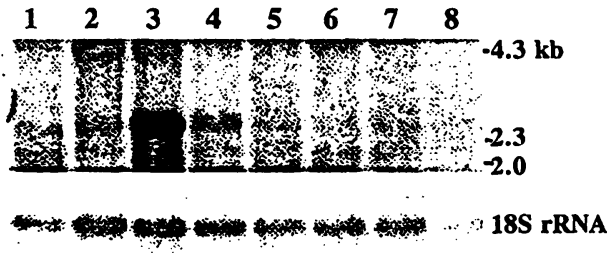

B

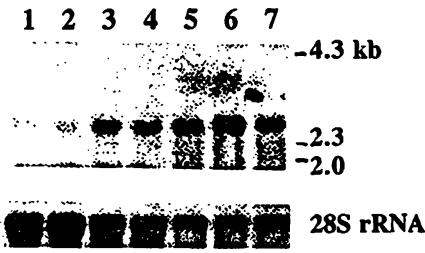

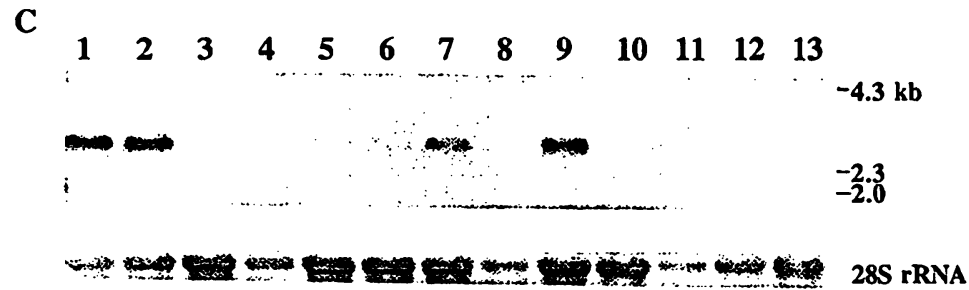

Fig. 2 Northern Blot Analysis of Human Organs (A), Cultured Keratinocytes and Skin Samples (B), and Rat Organs (C).

The following total RNA samples $(10 \mu \mathrm{g}$ ) were loaded on the blots: (A) Colon (lane 1), spleen (lane 2), placenta (lane 3), liver (lane 4), smooth muscle (lane 5), lung (lane 6), kidney medulla (lane 7), kidney cortex (lane 8); (B) keratinocytes cultured in KGM without (lane 1) or with 5\% FCS (lane 2), and shave biopsies from control skin (lanes 3 and 4) or psoriatic skin (lanes 5,6 and 7); (C) samples from 6 weeks old rats (lanes $1-8$ ) and 6 days old animals (lanes 9-13): Aorta stripped of adventitia (lane 1), total aorta (lanes 2 and 9), heart (lanes 3 and 10), spleen (lanes 4 and 11), kidney (lanes 5 and 12), lung (lanes 6 and 13), liver (lane 7) and gut (lane 8).

of rat $\mathrm{C} / \mathrm{EBP} \alpha$ is $91 \%$ homologous to the human sequence. At the nucleotide level the homology is over $89 \%$ within the coding sequences. When C/EBP $\alpha$ sequences of chicken (Calkhoven etal., 1992), Xenopus laevis (Xu and Tata, 1992) and Rana catesbeiana (Chen et al., 1994) are included in the alignment, the homologies are less pronounced and rather restricted to a few segments, which are located in protein domains probably involved in essential functions as transactivation ( $\mathrm{N}$-terminus, amino acid stretches 57 - 94, 132 - 185, 209 - 240; see Figure 1B), DNA-binding and dimerization (amino acid stretch 281 361).

While this manuscript was in preparation, another $\mathrm{hC} /$ $\mathrm{EBP} \alpha$ sequence was deposited in the EMBL/Genbank database (accession number U34070; ref. Antonson and Xanthopoulos, 1995). After a careful check of our experimental data, comparison of the two sequences revealed 13 differences ( 5 insertions/deletions, 8 substitutions; Figure 1A). These variations are apparently due to polymorphisms. It may still be relevant to note that the $\mathrm{G} / \mathrm{C}$ content of the coding sequences is over $74 \%$. The differences at the level of the nucleotide sequence predict $10 \mathrm{sub}$ stitutions in the polypeptide sequence. All amino acid substitutions occur in non-conserved parts of the sequence.

\section{Northern Analysis Reveals New Sites of C/EBPa Expression}

While the expression of $\mathrm{C} / \mathrm{EBP} \alpha$ in selected organs is well documented, we were eager to confirm preliminary observations of its presence in some additional organs. For this purpose, a series of northern blot analyses was performed on a collection of human RNA samples from selected organs/cells. This collection was extended with RNA samples isolated from rat organs, because the desired human organs/cells were not all available. Total RNA from se- lected human organs and keratinocytes cultured under various conditions was analyzed for $\mathrm{hC} / \mathrm{EBP} \alpha$ expression with the newly isolated autologous probe. The $2.7 \mathrm{~kb}$ transcript for C/EBP $\alpha$ was detectable in most organs tested except kidney cortex, but significant levels were present only in placenta, liver and spleen in decreasing order (Figure 2A: lanes 3, 4 and 2, respectively). In a separate experiment (Figure 2B) we tested hC/EBP $\alpha$ expression in a series of $0.2 \mathrm{~mm}$ shave biopsies of normal (lanes 3,4 ) and lesional psoriatic (lanes 5-7) human skin and in cultured human keratinocytes (lanes 1,2). Since significant and comparable expression levels could be detected in all samples tested, this result identified epidermal keratinocytes as a novel site for C/EBP $\alpha$ expression. Moreover, the analysis of rat RNA samples (Figure 2C) depicted aorta (lane 2) as an additional organ with abundant C/EBP $\alpha$ expression, especially when compared to the transcript levels present in liver (lane 7). As additional RNA samples we included aorta isolated from newborn rats, 6 days old (lane 9), and aorta from 6 weeks old rats stripped of the adventitia (lane 1) to exclude contamination of aorta with fat tissue. We did not analyze human aorta samples because this tissue was not available.

\section{Immunohistochemical Analysis of $h C / E B P \alpha$ in Human Epidermal Keratinocytes}

The next set of experiments was aimed at identifying the cellular source and localization of C/EBP $\alpha$ in human skin. The high homology between human and rat C/EBP $\alpha$ enabled us to use two characterized antisera raised against rat $C / E B P \alpha$ (see Materials and Methods). Staining protocols for these antisera were optimized on cryosections of mouse liver as a positive control (not shown). Figures $3 \mathrm{~A}$ and $3 B$ show the nuclear localization of C/EBP $\alpha$ in epidermal keratinocytes from normal skin and lesional psoriatic 
A

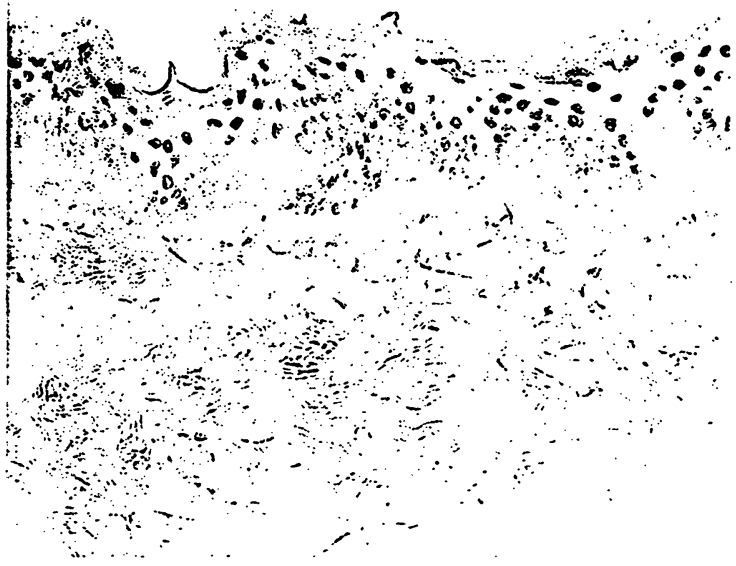

B

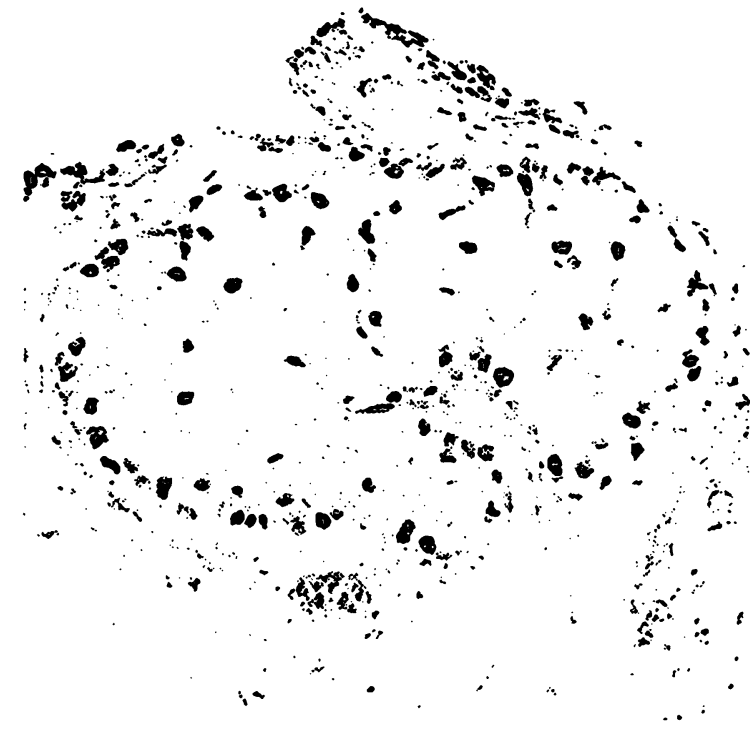

skin, respectively. The staining patterns of the epidermis were comparable for both antisera. The antiserum against the recombinant C-terminal 4/5 of rat $\mathrm{C} / \mathrm{EBP} \alpha$ gave the strongest signal and is shown here. Interestingly, the staining intensity was pronounced in the suprabasal cells, whereas the basal cells were negative to weakly positive. Although immunohistochemistry is - at best - semiquantitative, the staining intensity in psoriatic epidermis $(n=4)$ tended to be somewhat stronger than in normal epidermis $(n=4)$. No staining signal was observed in cells of the inflammatory infiltrate and the capillaries, which are abundantly present in lesional psoriatic skin. Hair follicle keratinocytes were also positive (not shown). Finally, glandular sebocytes, having an active lipid metabolism, displayed an intense staining in their nuclei (Figure 3C).

Cell culture of human epidermal keratinocytes is a convenient model to study normal and disturbed epidermal differentiation. First passage keratinocytes from healthy individuals were cultured in KGM (keratinocyte growth medium) without or with fetal calf serum. The limited de-
C

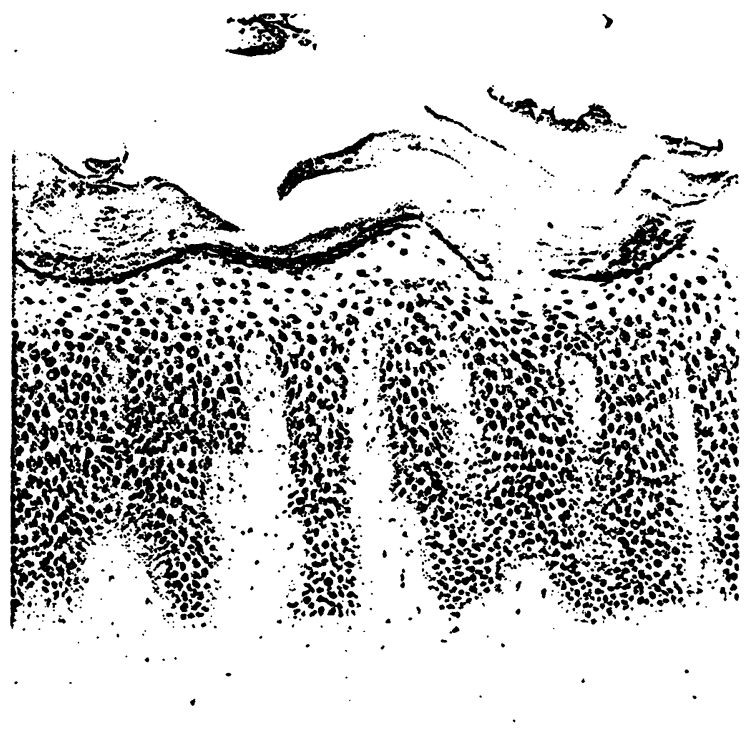

Fig.3 Immunohistochemical Analysis of Skin Biopsies.

(A) shows a characteristic staining pattern of normal skin, (B) of psoriatic skin, and (C) shows a sebaceous gland. $E=$ epidermis, $D=$ dermis, $S=$ sebaceous gland.

gree of differentiation observed under serum-free conditions was confirmed by the absence of the markers involucrin and SKALP/elafin (not shown). Under these conditions $\mathrm{C} / \mathrm{EBP} \alpha$ expression at the protein level was only detectable in a few scattered cells (Figure 4A). The number of nuclei positively staining for $\mathrm{C} / \mathrm{EBP} \alpha$ was significantly increased 48 hours after addition of FCS to confluent cultures (Figure 4B). The simultaneous strong induction of differentiation was assessed by the upregulation of involucrin, transglutaminase, SKALP/elafin and cytokeratin 16 (not shown). It is relevant to note that the transcript levels of $h \mathrm{C} / \mathrm{EBP} \alpha$ are apparently independent of the $a b-$ sence or presence of serum (Figure 2B).

\section{Discussion}

The functions and distribution of C/EBP $\alpha$ have been extensively studied in rodent cells and organs since its purification from rat liver nuclei and subsequent cloning of the 
A

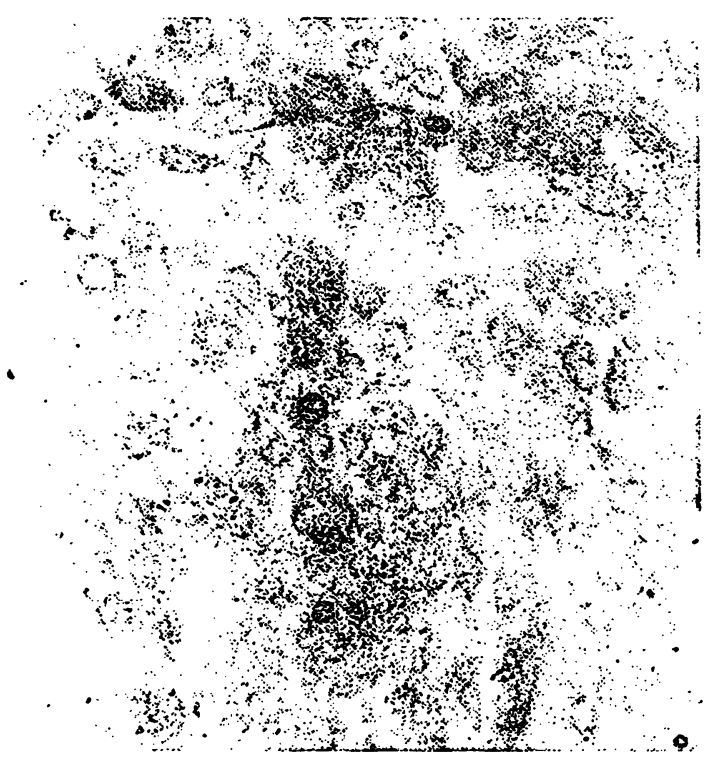

B

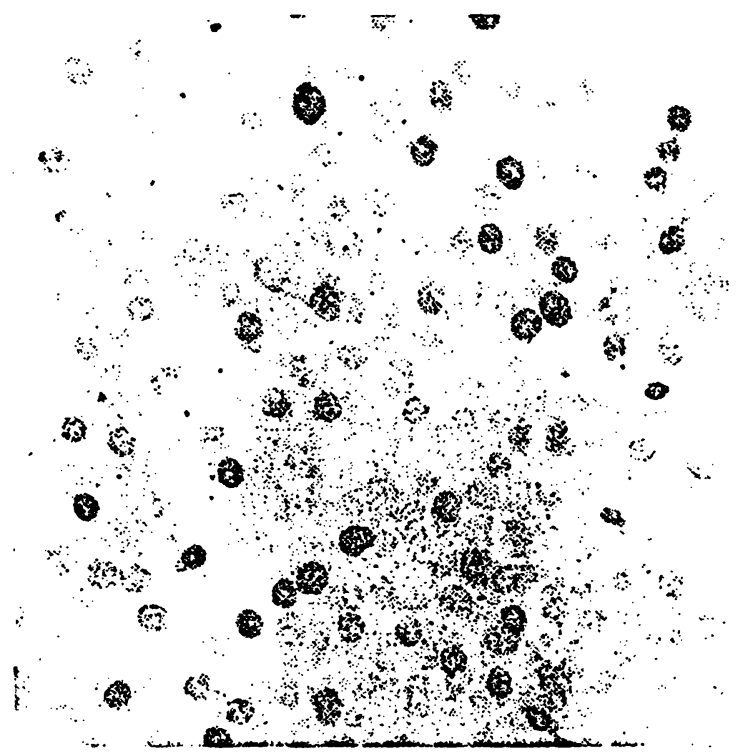

Fig.4 Immunohistochemical Analysis of Keratinocytes Cultured in KGM without (A) or with $5 \%$ FCS (B).

encoding CDNA and gene some ten years ago (Landschulz et al., 1988a). Highest expression levels are found in fat tissue, liver and placenta (Lincoln et al., 1994; Umek et al., 1991). In general, C/EBP $\alpha$ has been characterized as a central regulator of energy homeostasis in mammals and its presence is usually related with differentiation and growth arrest of involved cells, notably adipocytes and hepatocytes. Although C/EBP $\alpha$ is not completely restricted to the tissues mentioned, its expression elsewhere is detected only in specific subsets of cells. Within this context it is remarkable that the reported significant transcript levels of C/EBP $\alpha$ in two additional organs, the epidermal compartment of human skin and rat aorta, represent novel observations to our knowledge. The earlier claim of $\mathrm{C} /$ EBP $\alpha$ expression in mouse skin was not supported by experimental evidence (Umek et al., 1991). By immunohistochemical analysis with anti-ratC/EBP $\alpha$ antisera, we collected additional data that unequivocally assign the presence of C/EBP $\alpha$ to the nuclei of differentiated human keratinocytes. The isolation and characterization of a partial CDNA and a genomic copy of hC/EBP $\alpha$ should allow further elaboration of these observations.

Human epidermis, a stratified keratinizing epithelium (for review see Fuchs, 1990), consists of a basal, single cell layer with stem cells, and several suprabasal layers with terminally differentiating cells. The remnants of these cells consist of highly crosslinked protein structures embedded in lipids and form the stratum corneum, which functions as a main protective barrier at the surface of the organism. $\mathrm{C} / \mathrm{EBP} \alpha$ expression in the epidermis fits well with the active lipid metabolism of keratinocytes, especially in the stratum granulosum where the final enzymatic modifications take place to ensure a waterproof barrier. In addition to the epidermal keratinocytes, we noted a particularly strong $\mathrm{C} / E B P \alpha$ staining in the cells of sebaceous glands, which are also terminally differentiating cells devoted to lipid production. Inspection of the promoter regions of a number of genes coding for structural proteins expressed in suprabasal cells of normal and psoriatic epidermis reveals consensus C/EBP binding sites in the genes for several cytokeratins (CK1, CK6, CK10 and CK16), involucrin, and SKALP/elafin. Further studies are required to substantiate the suggested role of $\mathrm{C} / \mathrm{EBP} \alpha$ in epidermal lipid metabolism and to address a potentially broader involvement in terminal differentiation of keratinocytes. These issues have not been addressed in a recent report describing C/EBP $\alpha$ knockout mice, who died within 8 hours after birth because of an impaired energy homeostasis primarily affecting adipocytes and hepatocytes (Wang et al., 1995). No abnormalities were reported in the epidermis and sebaceous glands of these mice, but their early death may have veiled an effect of $\mathrm{C} / \mathrm{EBP} \alpha$ deficiency on normal air exposed mouse skin.

Although the mRNA quantities in psoriatic and normal human skin are similar, the immunohistochemical data suggest that $\mathrm{C} / \mathrm{EBP} \alpha$ protein levels are higher in psoriatic epidermis. This could be compatible with the finding that other differentiation-related genes are upregulated in psoriatic keratinocytes, including the expression of epidermal fatty acid binding protein (E-FABP) which is probably involved in lipid traffic (Siegenthaler et al., 1996). Several studies of C/EBP $\alpha$ distribution have shown that the transcript levels and the protein levels or transcription factor activity do not necessarily correlate with each other. Thus, regulation of $C / E B P \alpha$ levels must be in part posttranscriptional. A salient detail is the usage of alternative inframe translation start sites (Ossipowetal., 1993; Linetal., 1996; Calkhovenetal., 1994) giving rise to at least two functionally distinct isoforms, $357(42 \mathrm{kDa})$ and $238(30 \mathrm{kDa})$ amino acids long respectively. The full length product unambiguously activates transcription of responsive genes and is involved in the establishment of growth arrest, at least in adipocytes in cell culture. By contrast, the $\mathrm{N}$-terminally truncated product may either function as a 
repressor or an activator depending on the cellular context, but is unable to induce growth arrest (Lin et al., 1996).

During in vitro differentiation (that is, upon the addition of serum) the number of keratinocytes with C/EBP $\alpha$ positive nuclei apparently increases, while C/EBP $\alpha$ mRNA levels do not appear to change. The biological reason for this apparent discrepancy may be very interesting. Conceivably, differential C/EBP $\alpha$ translation, protein degradation, or nuclear translocation may account for these observations. It is clear that keratinocytes provide an interesting model for studying the role of C/EBP $\alpha$ in terminal differentiation, but the validation of this model will require a detailed analysis of the expression of the different $\mathrm{C} / \mathrm{EBP} \alpha$ polypeptide isoforms.

\section{Materials and Methods}

\section{RNA Isolation and Northern Blot Analysis}

Total RNA from tissues was isolated by the lithium-urea procedure (Auffray and Rougeon, 1980), and total RNA from cultured cells with RNAzol ${ }^{\mathrm{TM}}$ solution (Tel-Test, Friendswood, TX). Total RNA samples $(10 \mu \mathrm{g})$ were glyoxylated (McMaster and Carmichael, 1977), size fractionated on $1 \%$ agarose gels, and blotted onto Hybond $\mathrm{N}$-plus membranes (Amersham, Aylesbury, UK). The blots were afterwards hybridized with $18 \mathrm{~S}$ or $28 \mathrm{~S}$ ribosomal RNA probes as a calibration for equal loading in each lane.

\section{DNA Probes and Hybridization}

DNA probes were radiolabeled by the random prime labelling method (Feinberg and Vogelstein, 1984). Hybridization of the cDNA library was performed according to standard protocols (Sambrook et al., 1989).

\section{DNA Sequencing and Computer Analysis}

DNA fragments were sequenced according to the dideoxy method (Sanger et al., 1980) using a Sequenase sequencing kit (USB, Cleveland, Ohio). Large fragments were sequenced by constructing a set of deletion clones using exonuclease III (Erasea-base kit, Promega, Madison, Wisconsin). The sequence reported in this paper has been deposited in the EMBL database with accession number Y11525.

Identification of known sequences was performed using the EMBL/Genbank databases (Devereux et al., 1984; Pearson and Lipman, 1988). DNA sequence analysis, including searches for motifs, alignments, and structure predictions, was performed using the CAMMSA programs MOTIFS, PILEUP, CLUSTAL V, BESTFIT, PEPTIDESTRUCTURE, PLOTSTRUCTURE, and MEMBRANE PROPENSITY which are all part of the Wisconsin Package V 7.0 (Devereux et al., 1984).

\section{Skin Biopsies}

Shave biopsies ( $0.2 \mathrm{~mm}$ thickness) from the skin of healthy volunteers were taken with a keratome and used for primary keratinocyte cultures or RNA extraction. Punch biopsies ( $4 \mathrm{~mm}$ diameter) were taken for immunohistochemistry on cryosections.

\section{Primary Culture of Keratinocytes}

Primary cultures of normal human epidermal keratinocytes were obtained according to the Rheinwald-Green system (Rheinwald and Green, 1975). Suspensions of epidermal keratinocytes were seeded on lethally irradiated (3000 rad, $3 \mathrm{~min}$ ) Swiss mouse 3T3 fibroblasts in DMEM/F12 (3:1) (v/v) (Flow Laboratories, Irvine, Scotland) supplemented with $0.4 \mu \mathrm{g} / \mathrm{ml}$ hydrocortisone (Collaborative Research Inc. Lexington, MA, USA), $10^{-6} \mathrm{M}$ isoproterenol (Sigma, St. Louis, MO, USA), $100 \mathrm{U} / \mathrm{ml}$ penicillin and $100 \mu \mathrm{g} /$ $\mathrm{ml}$ streptomycin (Gibco, Breda, The Netherlands), 6\% FCS (Seralab, Nistelrode, The Netherlands), and $10 \mathrm{ng} / \mathrm{ml}$ EGF(Sigma, St. Louis, MO, USA). Cells were grown at $37^{\circ} \mathrm{C}, 95 \%$ relative humidity in air with $8 \% \mathrm{CO}_{2}$. EDTA-treated, trypsinized and liquid nitrogen stored keratinocytes from the primary culture were used in further experiments.

\section{First Passage and Induction of Keratinocyte Differentiation}

Keratinocytes were seeded at $10^{5}$ cells in KGM in $60 \mathrm{~mm}$ culture dishes as described previously (van Ruissen et al., 1994). KGM was composed of KBM (Clonetics, San Diego, CA, USA; $0.15 \mathrm{~mm}$ Calcium) supplemented with $0.1 \mathrm{~mm}$ ethanolamine (Sigma, St. Louis, MO, USA), $0.1 \mathrm{~mm}$ phosphoethanolamine (Sigma), 0.4\% (v/v) bovine pituitary extract (Clonetics), $10 \mathrm{ng} / \mathrm{ml}$ EGF (Sigma), $5 \mu \mathrm{g} / \mathrm{ml}$ insulin (Sigma), $0.5 \mu \mathrm{g} / \mathrm{ml}$ hydrocortisone (Collaborative Research Inc.), $100 \mathrm{U} / \mathrm{ml}$ penicillin and $100 \mu \mathrm{g} / \mathrm{ml}$ streptomycin (Gibco). The limited degree of differentiation observed in KGM without FCS was augmented after the addition of $5 \%$ FCS to confluent cultures. We previously described (Alkemade et al., 1994) that this system can be used to induce expression of involucrin and the epidermal proteinase inhibitor SKALP/elafin (Molhuizen et al., 1993) as respective markers for differentiation as seen in normal and psoriatic epidermis. Cultures were harvested for RNA extraction 48 hours after addition of $5 \%$ FCS. For immunohistochemical examination, cells were cultured on tissue culture coverslips (Thermanox, LAB-TEK Division, Miles Laboratories Inc., Naperville, IL, USA).

\section{Immunocytochemistry}

Biopsies from normal and lesional psoriatic skin were cryosectioned $(6 \mu)$ and fixed in $96 \%$ ethanol at room temperature for $10 \mathrm{~min}$. Cells cultured on coverslips were fixed using aceton/methanol $(1: 1 \mathrm{v} / \mathrm{v})$ and stored at $-20^{\circ} \mathrm{C}$. Before usage the coverslips were transferred to $4^{\circ} \mathrm{C}$ for $30 \mathrm{~min}$ and then dried by air exposure at room temperature. C/EBP $\alpha$ specific rabbit antisera, generously provided by $S$. McKnight and coworkers, were directed against a synthetic 14-mer peptide of rat C/EBP $\alpha$ or the recombinant $C$-terminal $4 / 5$ of rat C/EBP $\alpha$ (Landschulz et al., 1988a). Immunocytochemical stainings were performed using the Vectastain $A B C$ kit for polyclonal antibodies purchased from Vector Nector Laboratories Inc., Burlingame, CA, USA). After incubation with primary and secondary antibodies the sections and coverslips were incubated with diaminobenzidine tetrahydrochloride (DAB) substrate (metal enhanced DAB substrate Kit; Pierce, Rockford, Illinois, USA), and the reaction was terminated by incubating the coverslips in demineralized water. Cells were mounted in Permount (Fisher Scientific, New Jersey, USA) without counterstaining.

\section{Acknowledgements}

The authors acknowledge S. Klink for assistance during screening of the cDNA library, A. Geurts van Kessel and D. Olde Weghuis for the chromosome localization, $\mathrm{O}$. Madsen for performing a final check of the cloned DNA sequence and H.P.J. Bloemers for critical reading of the manuscript. 


\section{References}

Akira, S., Isshiki, H., Sugita, T., Tanabe, O., Kinoshita, S., Nishio, Y., Nakajima, T., Hirano, T., and Kishimoto, T. (1990). A nuclear factor for IL-6 expression (NF-IL6) is a member of a C/EBP family. EMBO J. 9, $1897-1906$.

Alkemade, J.A.C., Molhuizen, H.O.F., Ponec, M., Kempenaar, J.A., Zeeuwen, P.L.J.M., de Jongh, G.J., van Vlijmen-Willems, I.M.J.J., van Erp, P.E.J., van de Kerkhof, P.C.M., and Schalkwijk, J. (1994). SKALP/Elafin is an inducible proteinase inhibitor in human epidermal keratinocytes. J. Cell Sci. 107, 23352342.

Antonson, P., and Xanthopoulos, K.G. (1995). Molecular cloning, sequence and expression patterns of the human gene encoding CCAAT/enhancer binding protein alpha (C/EBP alpha). Biochem. Biophys. Res. Commun. 215, 106-113.

Auffray, C., and Rougeon, F. (1980). Purification of mouse immunoglobulin heavy chain mRNAs from total myeloma tumor RNA. Eur. J. Biochem. 107, 303-314.

Birkenmeier, E.H., Gwynn, B., Howard, S., Jerry, J., Gordon, J.I., Landschulz, W.H., and McKnight, S.L. (1989). Tissue-specific expression, developmental regulation, and genetic mapping of the gene encoding CCAAT/enhancer binding protein. Genes Dev. 3, 1146-1156.

Calkhoven, C.F., AB, G., and Wijnholds, J. (1992). cC/EBP, a chicken transcription factor of the leucine-zipper C/EBP family. Nucl. Acids Res. 20, 4093.

Calkhoven, C.F., Bouwman, P.R.J., Snippe, L., and AB, G. (1994). Translation start site multiplicity of the CCAAT/enhancer binding protein alpha mRNA is dictated by a small $5^{\prime}$ open reading frame. Nucl. Acids Res. 22, 5540-5547.

Cao, Z., Umek, R.M., and McKnight, S.L. (1991). Regulated expression of three C/EBP isoforms during adipose conversion of 3T3-L1 cells. Genes Dev. 5, 1538 - 1552.

Chen, Y., Hu, H., and Atkinson, B.G. (1994). Characterization and expression of C/EBP-like genes in the liver of Rana Catesbeiana tadpoles during spontaneous and thyroid hormoneinduced metamorphosis. Dev. Genet. 15, 366-377.

Darlington, G.J., Wang, N., and Hanson, R.W. (1995). C/EBP alpha: a critical regulator of genes governing integrative metabolic processes. Curr. Opin. Genet. Dev. 5, 565-570.

Descombes, P., and Schibler, U. (1991). A liver-enriched transcriptional activator protein, LAP, and a transcriptional inhibitory protein, LIP, are translated from the same mRNA. Cell 67, 569-579.

Devereux, J., Haeberli, P., and Smithies, O. (1984). A comprehensive set of sequence analysis programs for the VAX. Nucleic Acids. Res. 12, $387-395$.

Feinberg, A.P., and Vogelstein, B. (1984). A technique for radiolabeling DNA restriction endonuclease fragments to high specific activity. Addendum. Anal. Biochem. 137, 266 - 267.

Fuchs, E. (1990). Epidermal differentiation: the bare essentials. J. Cell Biol 111, 2807-2814.

Hendricks-Taylor, L.R., Bachinski, L.L., Siciliano, M.J., Fertitta, A., Trask, B., de Jong, P.J., Ledbetter, D.H., and Darlington, G.J. (1992). The CCAAT/Enhancer binding protein (C/EBP alpha) gene (CEBPA) maps to human chromosome 19q13.1 and the related nuclear factor NF-IL6 (C/EBP beta) gene (CEBPB) maps to human chromosome 20q13.1. Genomics 14, 12-17.

Landschulz, W.H., Johnson, P.F., Adashi, E.Y., Graves, B.J., and McKnight, S.L. (1988a). Isolation of a recombinant copy of the gene encoding C/EBP. Genes Dev. 2, 786-800.
Landschulz, W.H., Johnson, P.F., and McKnight, S.L. (1988b). The Leucine zipper: a hypothetical structure common to a new class of DNA binding proteins. Science 240, 1759-1764.

Lin, F.-T., MacDougald, O.A., Diehl, A.M., and Lane, M.D. (1996). A 30-kDa alternative translation product of the CCAAT/enhancer binding protein alpha message: transcriptional activator lacking antimitotic activity. Proc. Natl. Acad. Sci. USA 90, 9606-9610.

Lincoln, A.J., Williams, S.C., and Johnson, P.F. (1994). A revised sequence of the rat c/ebp gene. Genes Dev. 8, 1131-1132.

McMaster, G.K., and Carmichael, G.G. (1977). Analysis of single and double-stranded nucleic acids on polyacrylamide and agarose gels using glyoxal and acridine orange. Proc. Natl. Acad. Sci. USA 74, 4835-4838.

Molhuizen, H.O.F., Alkemade, H.A.C., Zeeuwen, P.L.J.M., de Jongh, G.J., Wieringa, B., and Schalkwijk, J. (1993). SKALP/ Elafin: an elastase inhibitor from cultured human keratinocytes. Purification, cDNA sequence and evidence for transglutaminase crosslinking. J. Biol. Chem. 268, 12028-12032.

Ossipow, V., Descombes, P., and Schibler, U. (1993). CCAAT/enhancer binding protein mRNA is translated into multiple proteins with different transcription activation potentials. Proc. Natl. Acad. Sci. USA 90, 8219-8223.

Pearson, W.R., and Lipman, D.J. (1988). Improved tools for biological sequence comparison. Proc. Natl. Acad. Sci. USA 85 2444-2448.

Rheinwald, J.G., and Green, H. (1975). Serial cultivation of strains of human epidermal keratinocytes: the formation of keratinizing colonies from single cells. Cell 6, $331-344$.

Sambrook, J., Fritsch, E.F., and Maniatis, T. (1989). Molecular cloning - a Laboratory Manual (Cold Spring Harbor, NY, USA Cold Spring Harbor Laboratory Press).

Sanger, F., Coulson, A.R., Barrell, B.G., Smith, A.J.H., and Roe, B.A. (1980). Cloning in single-stranded bacteriophage as an aid to rapid sequencing. J. Mol. Biol. 143, 161-178.

Siegenthaler, G., Hotz, R., Chatellard-Gruaz, D., Didierjean, L., Hellman, U., and Saurat, J.H. (1996). Purification and characterization of the human epidermal fatty acid-binding protein: localization during epidermal cell differentiation in vivo and in vitro. Biochem. J. 302, 363-371.

Umek, R.M., Friedman, A.D., and McKnight, S.L. (1991). CCAAT-Enhancer binding protein: a component of a differentiation switch. Science 251, 288-292.

van Ruissen, F., van Erp, P.E.J., de Jongh, G.J., Boezeman, J.B.M., van de Kerkhof, P.C.M., and Schalkwijk, J. (1994). Cell kinetic characterization of growth arrest in cultured human keratinocytes. J. Cell Sci. 107, 2219-2228.

Wang, N., Finegold, M.J., Bradley, A., Ou, C.N., Abdelsayed, S.V., Wilde, M.D., Taylor, L.R., Wilson, D.R., and Darlington, G.J. (1995). Impaired energy homeostasis in C/EBP-alpha knockout mice. Science 269, 1108-1112.

Williams, S.C., Cantwell, C.A., and Johnson, P.F. (1991). A family of C/EBP-related proteins capable of forming covalently linked leucine zipper dimers in vitro. Genes Dev. 5, 1553-1567.

Xu, Q., and Tata, J.R. (1992). Characterization and developmental expression of Xenopus C/EBP gene. Mech. Dev. 38, 69-81.

Received December 11, 1996; accepted March 12, 1997 
